$\mathrm{JD}$

78,7

18

Received 7 October 2020 Revised 30 March 2021 Accepted 1 April 2021

\section{Health-seeking behaviours of immigrants, asylum seekers and refugees in Europe: a systematic review of peer-reviewed articles}

\author{
Hamed Ahmadinia and Kristina Eriksson-Backa \\ Information Studies, Ảbo Akademi University, Turku, Finland, and \\ Shahrokh Nikou \\ Information Studies, Åbo Akademi University, Turku, Finland and \\ Stockholm University, Stockholm, Sweden
}

\begin{abstract}
Purpose - Immigrants, asylum seekers and refugees living in Europe face a number of challenges in accessing or using health information and healthcare services available in their host countries. To resolve these issues and deliver the necessary services, providers must take a comprehensive approach to better understand the types of health information and healthcare services that these individuals need, seek and use. Therefore, the purpose of this paper is to develop that comprehensive approach.

Design/methodology/approach - In this paper, a systematic literature review of peer-reviewed publications was performed, with 3.013 articles collected from various databases. A total of 57 qualifying papers on studies conducted in Europe were included in the review after applying the predefined inclusion and exclusion requirements, screening processes and eliminating duplicates. The information seeking and communication model (ISCM) was used in the analysis.

Findings - The findings revealed that while many health information and healthcare services are accessible in Europe for immigrants, asylum seekers and refugees, many of these individuals are unaware of their existence or how to access them. While our findings do not specify what health-related information these groups need, use or seek, they do suggest the importance and value of providing mental health, sexual health and HIV, as well as pregnancy and childbirth information and services. Furthermore, according to our results, health information services should be fact-based, easy to understand and raise awareness about healthcare structure and services available in Europe for this vulnerable population.

Practical implications - This study has a range of practical implications, including (1) highlighting the need for mental health and behavioural health services and (2) stressing the value of addressing cultural context and religious values while investigating (health) information seeking of people with foreign background.

Originality/value - This is one of the first studies to systematically review and examine the behaviour of immigrants, asylum seekers and refugees in relation to health information and healthcare services in the European context.
\end{abstract}

Keywords Asylum seekers, Europe, Healthcare services, Health-seeking behaviour, Health information, Immigrants, Refugees, Systematic review

Paper type Literature review

\section{Introduction}

Europe has historically faced several internal migrations and also migrations from other continents. There has been a significant increase in the number of people migrating to Europe in recent years. For example, the number of asylum seekers in Europe grew from 200,000 in 2008 to 1,400,000 in 2015 (Eurostat, 2020) and this figure is continuously rising. This has led to

(c) Hamed Ahmadinia, Kristina Eriksson-Backa and Shahrokh Nikou. Published by Emerald Publishing Limited. This article is published under the Creative Commons Attribution (CC BY 4.0) licence. Anyone may reproduce, distribute, translate and create derivative works of this article (for both commercial and non-commercial purposes), subject to full attribution to the original publication and authors. The full terms of this licence may be seen at http://creativecommons.org/licences/by/4.0/legalcode 
remarkable changes in the cultural, social, political, economic and healthcare structures of the European countries that are open to migration (Sansus et al., 2020, p. 59). People move to Europe for different reasons such as immigration, family ties, work, in search of refuge, or seeking for asylum due to political situations in their countries of origin (Van Mol and De Valk, 2016).

The provision of healthcare services to these individuals living in Europe is one of the most highly investigated problems. The importance of studying this demographic, especially their seeking behaviour for health information and healthcare services, is increasing as the number of residents with a foreign background in Europe continues to rise. Understanding what sort of health information and healthcare services this group of people needs, as well as how they pursue those information and services, is the first step towards addressing the challenges they may face.

In this study, we looked for scientific research on health information-seeking behaviour (HISB) and health-seeking behaviour. According to Lalazaryan and Zare-Farashbandi (2014), HISB refers to a range of possible situations, from an accidental exposure to health information, to the need for such information, as well as finding, selecting, using and even ignoring information. The HISB has been extensively researched among immigrants in the USA (e.g. Chen et al., 2010; Galeshi et al., 2018; Lee, 2018; Shin and Maupome, 2017; Yoon and Huang, 2017; Woodall et al., 2009). However, we found very few studies in Europe that focused on these groups. As a result, it was considered necessary and timely to concentrate on this demographic, extend the spectrum from health information-seeking behaviour to a broader viewpoint and examine the population's health-seeking behaviour. In this approach, we hope to look at research from the perspectives of both health-seeking behaviour and health communication. The existing studies that have focused on immigrants, asylum seekers and refugees in Europe have used common categories regarding the population's health-seeking behaviours. These studies have focused on topics such as healthcare needs, healthcare seeking, selection of healthcare sources, healthcare assessment and use, evaluation of health-seeking outcomes, health-seeking strategies and future healthcare seeking intentions; all from the patients' perspectives (Biswas et al., 2011; Gondek and Kirkbride, 2018; Onyigbuo et al., 2018).

In light of these categories, this research employs Robson and Robinson's (2015) information seeking and communication model to cover all specific aspects of the healthseeking process from the perspectives of both users and healthcare providers. In this paper, "users" refers to immigrants, asylum seekers and refugees residing in Europe, while "healthcare providers" refers to, e.g. healthcare professionals and medical staff. Moreover, in the European context, this study examines the experiences of healthcare professionals in terms of health information needs, information sharing with patients, evaluation and utilisation of health information and healthcare services by these individuals (Degni et al., 2012; Delilovic et al., 2018; Koehn, 2006; Misra et al., 2006b; Sundvall et al., 2018). By using the information seeking and communication model as a categorisation method, we hope to gain a holistic view of the phenomenon. We used this model to conduct a literature review of healthcare providers' perspectives on health communication needs, communication methods and communication barriers between healthcare professionals and their patients. To the best of our knowledge, there is a dearth of studies on the health information-seeking behaviours of immigrants, asylum seekers and refugees in Europe. Of the handful existing studies, few have been conducted on the behavioural aspects of health information-seeking (Devillanova, 2008; Ekblad et al., 2012; Garnweidner et al., 2013; Lecerof et al., 2011). Furthermore, a comprehensive analysis of the literature on the health information and healthcare service needs of immigrants, asylum seekers and refugees, as well as the type of information sought and used by them, and how they interpret the information received, is missing. As a result, this review paper seeks to fill this void by presenting new perspectives and highlighting areas that need more study. We hope to have answers to the following research questions in particular. 
$\mathrm{JD}$

78,7
$R Q 1$. From the perspective of immigrants, asylum seekers, and refugees residing in Europe, what are their health information and healthcare service needs, what types of health information and healthcare services are sought and used, and how do they evaluate such services?

$R Q 2$. From the healthcare providers' perspective, what type of health information and healthcare services are used, and how do they evaluate the health-seeking behaviour of immigrants, asylum seekers and refugees residing in Europe?

\section{Methods}

To pursue the aim of this study, a literature search was conducted in October 2019, using the preferred reporting items for systematic reviews and meta-analyses (PRISMA) guidelines (Shamseer et al., 2015). The primary goal of this study was to focus on the health informationseeking behavior of immigrants, asylum seekers and refugees living in Europe, as there have been few studies on this subject (see, e.g. Ekblad et al., 2012; Lecerof et al., 2011). In this study "health information-seeking behaviour" refers to individuals' use of specific actions and/or strategies to acquire health information (Lambert and Loiselle, 2007, p. 1,008). This approach includes HISB processes related to how individuals cope with health-threatening situations (Davison et al., 2002; Garvin et al., 2003; Hoskins and Haber, 2000; Ransom et al., 2005; Rees and Bath, 2000). In addition, we also focused on studies of health-seeking behaviours as problem-focused coping strategies adopted by patients and healthcare providers as responses to threatening situations (Rees and Bath, 2000). We argue that this approach will provide a better understanding of which health information and healthcare services are needed, sought and used by this target group.

In order to be as comprehensive as possible and include all relevant information, we considered qualitative, quantitative and mixed-methods studies as well as the case reports provided that they were original studies and published in peer-reviewed journals or conference proceedings. To be included in the review, studies had to (1) be published in English or English along with another language, (2) focus on human health-related issues, (3) focus on immigrants, asylum seekers and/or refugees residing in Europe and (4) be original studies, not a brief review of an original study published in a conference paper or editorial note. Since our focus was on specific target groups in Europe, other minorities such as indigenous ethnic minorities or subcultures (e.g. Sámi-speaking minorities in Finland, Sweden or Norway) were excluded. Furthermore, studies were also excluded if they focused primarily on the legal or political aspects of healthcare service provision for refugees and/or asylum seekers, rather than focusing their health-seeking behaviour.

\section{Search terms}

The search consisted of free terms related to the main objectives of the study, and truncation $\left(^{*}\right)$ as well as research subject terms and keywords were used. The search terms were combined by using the Boolean operators "AND" and "OR." In addition, the terms "asylum seeker," "refugee" and "immigrant" along with all their synonyms and related terms were combined with proximity operators with a distance space of 10 (adj 10) to retrieve more results. The formulated search statement of this study was as follows:

((health information OR health seek* OR health help* OR care seek* OR health behavi* OR health commun* OR information practice* OR information literacy) AND (emigra* OR immigra* OR refuge* OR asylum seek* OR foreign* OR migra*)).

\section{Study model}

The information seeking and communication model (ISCM) was used to categorise the articles (Robson and Robinson, 2015). This model was developed to track information sharing 
and communication between users and providers (see Robson and Robinson, 2015, p. 1,045). In our study, as mentioned earlier, users were immigrants, asylum seekers or refugees residing in Europe, and providers were healthcare providers in Europe. Moreover, this model also covers all factors relevant to health information-seeking behaviour such as information needs, information seeking, selection of information sources and information assessment, use or dismissal. The ISCM is a relatively new and a more comprehensive model compared to previous models of information seeking and communication, such as those developed by Wilson (1981) and Ellis (1989). Moreover, the ISCM was developed building on previous models from the fields of library and information science (LIS) and communication studies (e.g. Dervin, 2005; Ellis, 1989; Ingwersen and Järvelin, 2005; Johnson, 1997; Thackeray and Neiger, 2009; Wilson, 1981).

We categorised our selected articles according to the information seeking and communication model aiming at analysing and interpreting the findings from healthseeking behaviour research and to explore factors influencing this process in the studied groups of people. We reinterpreted the model from information seeking behaviour to healthcare seeking in order to explore the topic and shed light on different aspects of the phenomenon from both providers and users' points of view. We did not consider any labelling for the last step of the ISCM, which refers to the user needs' satisfaction from the healthseeking process. The satisfaction, if mentioned in the selected studies, is described in relevant sections either in the summary of findings or when answering the research questions. The following categories were created based on the original model:

(1) User: needs/wants/goals/perception.

(2) User: assess/use/ignore communication.

(3) User: communication medium/process.

(4) Provider: needs/wants/goals/perception.

(5) Provider: assess/use/dis-/misinformation.

(6) Provider: communication medium/process.

(7) Health or information seeking activity/feelings/thoughts.

(8) Source selection: credibility/utility.

(9) Outcome: actions/decisions/knowledge.

(10) Future information seeking.

\section{Search strategy}

We searched scientific databases through Web of Science (WoS) and EBSCO for peerreviewed journal articles, conference papers, books and book chapters. From WoS, we selected all available databases, including Web of Science Core Collection; KCI Korean Journal Database; Medline; Russian Science Citation Index and SciElo Citation Index. The rationale behind including the KCI Korean Journal Database and the Russian Science Citation Index was that they contain studies on Korean immigrants, and Russian immigrants or asylum seekers in Europe. From EBSCO, we selected all databases related to library and information sciences and health communication, including Academic Search Premier, Library, Information Science and Technology Abstracts (LISTA), Communication and Mass Media Complete, Cumulative Index to Nursing and Allied Health Literature (CINAHL), eBook Collection (EBSCOhost), The Cochrane Library, PsycINFO and PsyARTICLES. Educational Resource Information Center (Eric) and Comprehensible Language and Effective information and healthcare services 
$\mathrm{JD}$

78,7

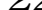

22

Table 1.

Search strategy keywords, inclusive and exclusive terms
Communication (CLEC) from EBSCO were eliminated because the findings were either duplicates of documents collected from other databases or did not contain relevant studies.

\section{Selection of studies}

Studies were selected based on the research model in three phases: reviewing titles, abstracts, keywords and full-text records. All databases were searched simultaneously, and records were extracted either directly or through Publish or Perish Version 7.11 [1]. We used Rayyan [2] website and mobile application for conducting the systematic review. This tool is designed to help researchers in screening and selecting records based on the PRISMA guidelines. In the review phase, the first author screened all records and excluded those that did not fit to any of the categories created based on the ISCM (Robson and Robinson, 2015). We tried different strategies for selecting records conducted in Europe. In order to be sure that the studies are conducted in a European country, we read abstracts and methods of the articles. Table 1 shows the keywords used in the screening process.

In the second phase, abstracts of the selected articles were double-checked by all authors. Finally, full texts were screened for relevance by the first author and checked for accuracy by the co-authors.

\section{Full text review: data extraction and search results}

A code was developed for data extraction. The code captured general information of the studies (author, publisher, publication type and year), characteristics of the population studied (sample size, sample group background, place of recruitment and countries where the studies were conducted), methodological components (study design, methodological characteristics and means of data gathering), themes, objects and study results. A total of 3,013 records were retrieved from 12 databases. In addition to excluding the duplicated records, we removed the records if they were not available in English, within the relevant research domain, available in full text or did not match the criterion about the publication type. As such, we ended up with 947 articles. After title and abstract screening and removal of irrelevant records, 57 articles remained as the final sample (see Appendix 1). Figure 1 presents a complete overview of the whole screening and selection process.

\section{Characteristics of the included studies}

The final list (57 articles) addressed a wide variety of themes, including information about different health issues (e.g. cardiovascular disease, diabetes, diet and nutrition, mental health, oral health, perinatal health, pregnancy and childbirth, sexual health and HIV) and issues experienced by healthcare providers (e.g. communication and cultural issues, attitudes and perceptions as well as the research methods (see Table 2).

Keywords

Title ((health information OR health seek* OR health help* OR care seek* OR health behavi* OR health commun* OR information practice* OR information literacy) and (emigra* OR immigra* OR refuge* OR asylum seek* OR foreign* OR migra*))

Inclusive European countries

Exclusive Sub-culture, systematic review, literature review, editorial notes, human rights, health law, role of the employer, ambulatory care, safety science, mediators, education and debate, health information systems, health promotion, health policy and practice, faith-based community action, medicine and medical science and public health 


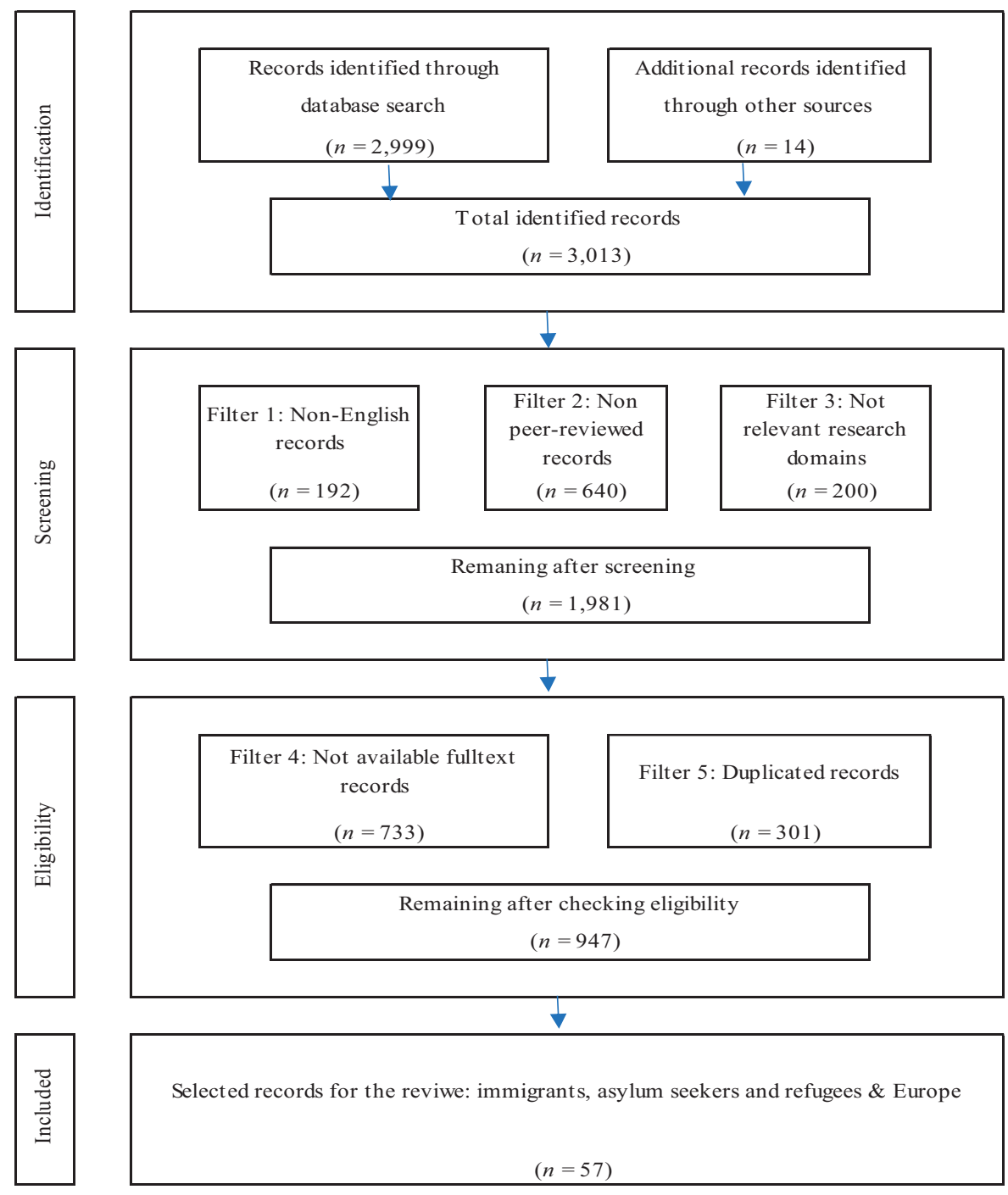

$\begin{array}{r}\text { Health } \\ \text { information } \\ \text { and healthcare } \\ \text { services } \\ 23 \\ \hline\end{array}$

Figure 1.

Flowchart of the selection process

In studies on health-seeking behaviours, a qualitative approach (50\%) was the most widely used methodology, and more than half of the studies focused on specific health-related issues $(61.40 \%)$. In addition, the largest share of studies on mental health adopted a qualitative approach $(47.36 \%$ ), while 22 out of 57 selected studies did not focus on any particular health related theme as specified in Table 2. Some studies objectively focused on topics such as informing, educating or helping patients to decide on their health issues (e.g. Knipscheer and Kleber, 2001; Knipscheer and Kleber, 2005; Leavey et al., 2007; Lecerof et al., 2011; Straiton et al., 2018), and others objectively focused on understanding the healthcare provider's perceptions, attitudes and challenges in health services provision (e.g., Delilovic et al., 2018).

Appendix 1 and Appendix 2 provide additional information on the articles such as categories, participants (place of recruitment) and means of data gathering, a descriptive 
JD

78,7

\section{4}

Table 2.

Key findings on healthseeking behaviours of immigrants, asylum seekers and refugees in Europe

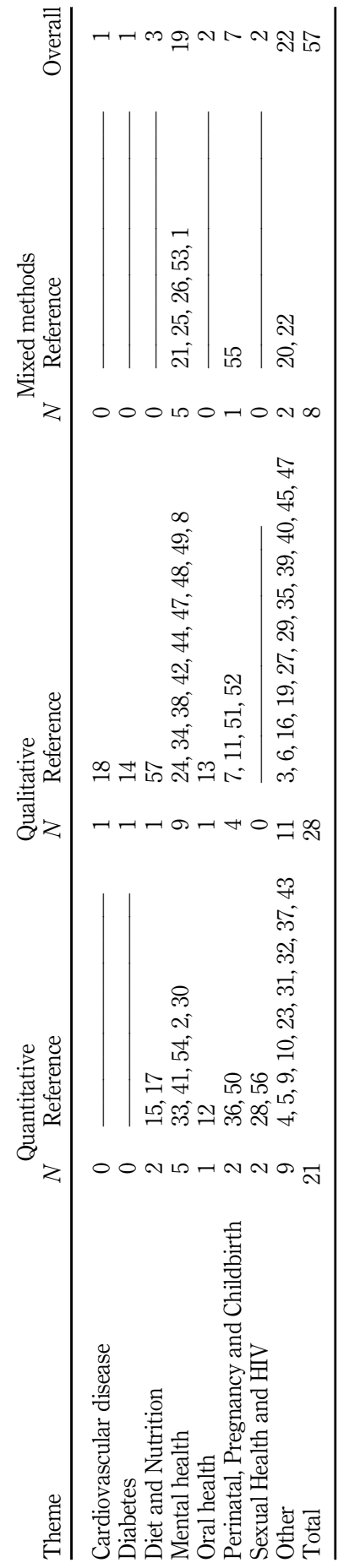


summary of the selected studies including the country, participants (sample size, ethnic background of sample group). The largest share of studies was conducted in the United Kingdom, Sweden, The Netherlands and Germany ( $75.44 \%$ ), while the rest were conducted in seven other European countries. Interviews and semi-structured interviews were the most common means of data gathering for qualitative studies $(36.84 \%)$, whereas questionnaires were most commonly used in quantitative studies $(15.79 \%)$. A mixed-methods approach was adopted in $14.03 \%$ of the studies. More than half of the studies had small sample sizes (1-100); the majority of participants were of African or Middle East background (59.65 and 50.88\%, respectively). Participants were mainly recruited through hospitals, clinics, health centres $(33.33 \%)$, voluntary groups, cultural communities $(28.07 \%)$ or refugee camps or refugee reception centres $(17.54 \%)$ (see Appendix 1 and 2 ).

\section{Summary of findings based on the research categories}

The results showed that most of the studies focused on users' points of view and covered issues related to needs $(24.56 \%)$, use $(28.07 \%)$ and communication medium and process $(8.77 \%)$. Health communication medium and process $(8.77 \%)$, healthcare needs $(7.02 \%)$ and healthcare use $(1.75 \%)$ were also discussed from healthcare providers' points of view. We also found discussions on other issues such as information seeking $(26.32 \%)$, source selection $(8.77 \%)$, outcomes $(8.77 \%)$ and further information seeking $(1.75 \%)$. The largest number of studies on using health services had participants with either African or the Middle East ethnic backgrounds ( 81.25 and $56.25 \%$, respectively). These studies highlighted issues related to the provision of access to medical services for asylum seekers, refugees and immigrants in Europe (see Appendix 1). Next, we present findings based on our model of study.

User: needs/wants/goals/perception. In total, fourteen articles discussed and covered the various types of health services that asylum seekers need, using either qualitative or quantitative approaches (see Appendix 1). These studies emphasised that mental health services were highly needed (e.g. Bartolomei et al., 2016; Djuretic et al., 2007; Gondek and Kirkbride, 2018; Kleinert et al., 2019; Laban et al., 2008; Maier and Straub, 2011; Misra et al., 2006a; Palmer, 2007; Papadopoulos et al., 2003). However, healthcare services related to respiratory diseases, infections, musculoskeletal or connective tissue problems, gastrointestinal issues, injuries, perinatal health, pregnancy and childbirth, as well as diet and nutrition were also found to be needed (Garnweidner et al., 2013; Gewalt et al., 2018; Goodman et al., 2018; Emtell Iwarsson et al., 2019). Misra et al. (2006a) argued that providing health services for asylum seekers and refugees, due to their complex needs, must be broad-based and include social service and advocacy groups, as well as primary care and specialised mental health services.

User: assess/use/ignore communication. Sixteen articles covered issues related to assessing or using healthcare services. More than half of the studies were conducted in non-English speaking countries (e.g. Denmark, Finland, Germany, The Netherlands and Portugal), mostly with participants with either African or Middle Eastern backgrounds. These studies reported challenges with accessing or using psychiatric and psychotherapeutic treatments, sexual health and HIV treatments, pregnancy and childbirth services or with obtaining dental check-up appointments (Dias et al., 2020; Erdsiek et al., 2017; Jayaweera and Quigley, 2010; Knipscheer and Kleber, 2001, 2005; Mattila et al., 2016; McMunn et al., 1998; Nikendei et al., 2019; Toar et al., 2009).

Moreover, participants reported differences in access to or the use of health services based on their ethnic backgrounds (Gerritsen et al., 2006). In addition, the participants (asylum seekers, refugees and immigrants) mentioned that factors such as migration status, length of residency, educational background and cultural norms and values have a significant influence on their choice and use of health services (Erdsiek et al., 2017; Hansen et al., 2008; Knipscheer and Kleber, 2001). 
JD

78,7

Participants in the studies conducted in the United Kingdom and Ireland had different attitudes towards assessing, using or dismissing health communication (e.g., Kang et al., 2019). They also indicated some challenges and difficulties in relation to navigating health communication or negotiating primary care services (Kang et al., 2019, p. 541). Such challenges rooted in the language barriers, inadequate interpretation services, lack of awareness of the structure and function of the national health system, difficulties meeting the costs of dental care, prescriptions, transportation and perceptions of discrimination in terms of race, religion and immigration status (Kang et al., 2019, p. 537). The main reasons for using health services in studies conducted in the United Kingdom were related to psychiatric, musculoskeletal and dermatological treatments (Carruthers and Oakeshott, 2019).

Regarding factors influencing the use of health services, local and transnational social networks, ethnicity, birthplace and length of residency in the host country were found to impact migrants' health decision-making processes (Jayaweera and Quigley, 2010; Thomas, 2010). In a comparative study on self-reported health and healthcare utilisation, Toar et al. (2009) found that asylum seekers and refugees living in Western countries need healthcare services related to mental health issues, especially about posttraumatic stress disorder (PTSD). In addititon, a strong need for health information related to HIV/AIDS prevention was found in two studies on Sub-Saharan African and African migrant communities (respectively, in Portugal and the UK) (Dias et al., 2020; McMunn et al., 1998). For example, Dias et al. (2020) argued that current HIVprevention interventions, especially HIV testing, are not reaching the target groups, and most likely prevention opportunities are being missed. This result indicated that Sub-Saharan African migrants probably are not aware of available sexual health services, for instance, sexual/reproductive health consultations. Therefore, the rate of using health services among these immigrants in Portugal is very low. Similarly, Mediterranean migrants with lower education in The Netherlands reported a more negative attitude towards consulting mental health services, mostly due to being less familiar with the services (Knipscheer and Kleber, 2005). Finally, a study on migrants from the former Yugoslavia living in the UK disclosed difficulties and challenges in adapting to a new healthcare system. The results highlighted a reflection of cultural appropriateness of mainstream services that led to constrains in service use (Djuretic et al., 2007). Furthermore, a quantitative study with participants with Asian and African ethnic backgrounds suggested that "in order to conduct a study on health and healthcare utilisation among asylum seekers and refugees, it is important to adopt a crosscultural adaptation of the chosen measurement instruments, translation and back translation only is not sufficient" (Gerritsen et al., 2004, p. 9).

User: communication medium/process. Five articles focused on health communication media and processes. On the one hand, from a user point of view, trust is a key to facilitate health communication between healthcare providers and users who are refugees or residents with different ethnic backgrounds (Feldmann et al., 2007; Garnweidner et al., 2013). For instance, midwifes were mentioned as trustworthy sources of nutrition-related information during antenatal care of pregnant women with different ethnic backgrounds residing in Norway (Garnweidner et al., 2013). On the other hand, findings from studies on undocumented immigrants and refugees emphasised the significant role of social information networks and transnational health networks as health communication media (Devillanova, 2008; Thomas, 2010). Finally, a study on vulnerable groups of Arabic- and Somali-speaking asylum seekers in Sweden reported that "providing health information in a host country through official channels needs to be based on fact-based information, and patients need to be treated with concern and respect" (Ekblad et al., 2012, p. 21).

Provider: needs/wants/goals/perception. Four studies covered issues related to healthcare providers' needs and goals in healthcare settings. The main topics of these studies were related to mental health services. Interviews were the most common form of data collection in studies conducted on immigrants, asylum seekers, refugees and healthcare providers in Sweden and 
the UK (Delilovic et al., 2018; Misra et al., 2006b; Palmer, 2007). In addition, healthcare providers in a study conducted on asylum seekers originating in Asia, the Middle East and the Indian subcontinent mentioned their difficulties in decoding languages of distress, and understanding trauma and subjective meanings of suicide, challenges of combining patients and their perspectives and a sense of shared powerlessness (Sundvall et al., 2018). Moreover, healthcare professionals in a study investigating the experiences of professionals who treat asylum seekers and refugees argued that "it is hard to explore health problems such as depression or somatisation as they felt that the interpreter may not be accurately translating the words, or there may not be a word for depression in the language being used" (Misra et al., 2006b).

Still, in a study exploring healthcare provider perspectives on health examinations for asylum seekers in Sweden, healthcare professionals encountered challenges including intercultural competence, guidelines and tools on how to appropriately assess mental health and individuals' willingness to disclose personal experiences (Delilovic et al., 2018). A study on asylum seekers and refugees living in the UK provides some practical solutions to cover health service providers' needs while providing services for this vulnerable patient group. Health service providers need to be aware of the cultural, social and political context within which individuals operate and are judged. Furthermore, healthcare providers need to have education and training programmes to incorporate the understandings and allow for considered and sensitive exploration of the belief systems operating in asylum seekers and refugees' communities (Misra et al., 2006b). Finally, healthcare providers need to develop their treatment programmes for this group of patients as a flexible, preventative approach based on different, complex, individual requirements, allowing for inclusion of traditional and alternative treatment options and longevity of treatment programmes (Misra et al., 2006b).

Provider: assess/use/dis-/misinformation. Among the studies selected for the review, we found an interesting comment related to the healthcare provider assessment and dis-/ misinformation. In a study conducted on female suicidal asylum seekers living in the UK, mental healthcare providers reported challenges related to understanding unfamiliar expressions; particularly, cultural idioms of distress (Sundvall et al., 2018).

Provider: communication medium/process. On the providers' side, the communication medium and process were pointed out by five articles covering topics including mental health, perinatal health, pregnancy and childbirth. Two studies mentioned that healthcare providers and patients' problems were grounded in the communication (including linguistic difficulties), cultural traditions and religious beliefs (Degni et al., 2012; Reynolds and White, 2010). In another study, healthcare providers were recommended to implement an approach that considered asylum seekers' cultural beliefs and traditional health practices in order for their patients to adhere to treatment recommendations (Koehn, 2006). Moreover, in a qualitative study conducted in Sweden focusing on the communication challenges between healthcare providers and patients, Sundvall et al. (2018) revealed that such communication is often affected by, e.g. the unbearable realities of the women, difficulties for clinicians in decoding languages of distress and understanding trauma and subjective meanings of suicide, as well as challenges with combining patients' and clinicians' perspectives, and a sense of shared powerlessness. In accordance with this result, asylum seekers in another Swedish study argued that due to poor communication, inadequate information and lack of clarity regarding the aim of health examinations, they felt that they received insufficient information both ahead of and during the health examination (Delilovic et al., 2018).

Health or information seeking activity/feelings/thoughts. This section covers studies on healthcare seeking and activities, and feelings or thoughts during this process, rather than health information-seeking which was rarely mentioned in the findings. The findings can, however, reveal possible activities, feelings or thoughts related to the information-seeking behaviour of the studied groups. The activity of seeking health services and expressing feelings and thoughts about the health services were discussed in 15 studies. First, in terms of 
JD

78,7

activities and thoughts, the importance of cultural values and religion within health seeking were highlighted in ten studies on mostly African migrants, whereas one study focused on immigrants with multi-ethnic backgrounds (Garnweidner et al., 2013; Gilgen et al., 2005; Hjelm and Apelqvist, 2016; Jensen et al., 2014; Knipscheer and Kleber, 2001; Onyigbuo et al., 2016; Onyigbuo et al., 2018; Palmer, 2007; Straiton et al., 2018; Teunissen et al., 2014). For instance, religion was pointed out to have impact on health-related lifestyle behaviour of firstgeneration Polish immigrants living in Germany (Morawa and Erim, 2018). Second, feelings and thoughts related to health seeking were found to be influenced by the education and the awareness of treatment opportunities, and by whether general medical care was perceived to be designed to meet patients' needs and expectations (Dorn et al., 2011; Garnweidner et al., 2013; Gilgen et al., 2005; Hjelm and Apelqvist, 2016; Onyigbuo et al., 2016; Straiton et al., 2018). Participants pointed out mental health services as the most sought-for health services, especially among immigrants from Africa, Asia, the Indian subcontinent and the Middle East (Teunissen et al., 2014; Leavey et al., 2007; Palmer, 2007; Straiton et al., 2018). Finally, acculturation, coping style, beliefs about healthcare and illness and their impact on self-care and care-seeking, recognition of symptoms, as well as cultural care were mentioned as factors influencing health seeking behaviour (Hedemalm et al., 2008; Hjelm and Apelqvist, 2016; Onyigbuo et al., 2016, 2018).

Source selection: credibility/utility. Five studies pointed out some factors affecting selection and utility of healthcare services. On the one hand, studies on female asylum seekers revealed significant influence of behavioural factors, language and culture on accessing perinatal services, resources and information (Barkensjö et al., 2018; Reynolds and White, 2010). For instance, a study on perinatal health services found that when healthcare providers express empathic concern and have a listening behavioural approach towards their patients, patients feel empowered, acknowledged and encouraged, leading them to trust clinicians and diminishing fear relating to seeking healthcare services (Barkensjö et al., 2018). Another study conducted in the UK showed that the working environment of healthcare staff affects the services that they could provide to asylum-seeking women who were pregnant or had young babies (Reynolds and White, 2010). On the other hand, a study on Ethiopian refugees showed that the state of being a refugee has had impact on their health beliefs and practices (Papadopoulos et al., 2003). Furthermore, a study on undocumented migrants in Germany revealed that migration status has significant impact on the ignoring of health problems until they reach an acute and potentially life-threatening stage (Huschke, 2014).

Finally, a study about providing online information in primary care services for refugees and asylum-seekers showed that even though the majority of local statutory organisations, which are responsible for improving public health provide good information regarding coordination of services and evidence of a thorough health needs assessment; there is, however, a need for considerable work if the requirements for access to high quality information about services of the public and government are to be met (Kralj and Barriball, 2004).

Outcomes: actions/decisions/knowledge. This section covers five studies exploring factors influencing health outcomes. First, health literacy and educational level were reported to be the most important factors influencing health information-seeking outcomes for asylum seekers, refugees and immigrants (Lecerof et al., 2011; Wångdahl et al., 2018). Health literacy refers to accessing, understanding, appraising and using health information (Sørensen $e$ c al., 2012). Wångdahl et al. (2018) argued that "the outcome of healthcare-seeking is associated with comprehensive health literacy (CHL) and found that a considerable proportion of the refugees in Sweden have limited CHL, and report less than good health and impaired wellbeing, or that they have refrained from seeking healthcare" (p. 410). Lecerof et al. (2011) and Wangdahl et al. (2018) argued that the asylum seekers, refugees and immigrants' health literacy level have impact on their health outcomes. Moreover, educational background and lack of health information were reported to have significant effects on the studied groups' 
health decision-making processes (Lecerof et al., 2011). Second, factors including untreated mental conditions and patients ethnocultural background were mentioned in studies on health outcomes among asylum seekers in Finland and Germany (Bozorgmehr et al., 2018; Koehn, 2006). In addition, access to medical attention for routine check-ups, lack of awareness of primary medical care's surgery hours, perception of symptoms of illness, the role of nurses in asylum seekers' healthcare seeking, language translation services in primary care and the role of specialists' help in medical settings were all mentioned as more general factors influencing health outcomes of asylum seekers living in the UK (O'Donnell et al., 2007).

Future information seeking. Future information seeking was not mentioned in the selected studies in this systematic review; however, findings from a study on undocumented immigrants living in Denmark showed that future health-seeking strategies included selfmedication, contacting doctors in the home countries and borrowing health insurance cards from Danish citizens (Biswas et al., 2011). The main reason behind seeking alternative health services has rooted in having restricted access to healthcare; in particular, limited medical services rights, healthcare professionals' arbitrary attitudes, fear of being reported to the police, poor language skills, lack of local social networks, lack of knowledge about the healthcare system and lack of knowledge about informal networks of healthcare professionals, were the most important ones (Biswas et al., 2011).

\section{Answering the research questions}

Two main broad research questions were formulated in this study. The first question asks, "from the perspective of immigrants, asylum seekers, and refugees residing in Europe, what are their health information and healthcare service needs, what type of health information and healthcare services are sought and used, and how do they evaluate such services?" Many asylum seekers and refugees expressed a strong need for mental health services as a consequence of the stress entailed by immigration and asylum-seeking processes (Bartolomei et al., 2016; Djuretic et al., 2007; Gondek and Kirkbride, 2018; Kleinert et al., 2019; Knipscheer and Kleber, 2001, 2005; Laban et al., 2008; Leavey et al., 2007; Maier and Straub, 2011; Misra et al., 2006a; Nikendei et al., 2019; Palmer, 2007; Papadopoulos et al., 2003; Straiton et al., 2018; Teunissen et al., 2014; Toar et al., 2009). Asylum seekers and refugees in other studies expressed they need health service related to respiratory problems, infections, muscular and skeletal issues, and injuries (Goodman et al., 2018).

The majority of studies highlighted the influence of culture and religion on the healthseeking behaviour of asylum seekers, refugees and immigrants in Europe (Hjelm and Apelqvist, 2016; Morawa and Erim, 2018; Onyigbuo et al., 2016; Onyigbuo et al., 2018; Papadopoulos et al., 2003; Straiton et al., Teunissen et al., 2014). For example, undocumented immigrants in The Netherlands reported that they seek healthcare advice first through their friends, religious leaders and religious communities, and lastly, through physicians (Teunissen et al., 2014). Moreover, Nigerian clergy and healthcare professionals living in the United Kingdom also mentioned using religious and cultural care along with formal healthcare methods in their health information-seeking processes (Onyigbuo et al., 2016).

Even though our findings are not directly describing what health-related information is needed, used, our sought by immigrants, asylum seekers and refugees residing in Europe, the findings of this review study highlight the importance of providing health-related information about mental health, sexual health and HIV, pregnancy and child birth for them (e.g., Barkensjö et al., 2018; Dias et al., 2020; Kleinert et al., 2019; Straiton et al., 2018). Also, health information should be fact-based, easy to understand and raise awareness about healthcare structures and health services which are available for this vulnerable group of residents in Europe (e.g. Ekblad et al., 2012; Hjelm and Apelqvist, 2016; Kang et al., 2019; Onyigbuo et al., 2016; Straiton et al., 2018). 
$\mathrm{JD}$

78,7

The second research question asks, "from the healthcare providers' perspective, what type of health information and healthcare services are used, and how do they evaluate the healthseeking behaviour of immigrants, asylum seekers, and refugees residing in Europe?" Not surprisingly, healthcare providers mentioned challenges related to communication with the patients while they are providing health services related to mental health, perinatal health, pregnancy and childbirth (Delilovic et al., 2018; Degni et al., 2012; Koehn, 2006; Reynolds and White, 2010; Sundvall et al., 2018). Apart from difficulties related to assessing the patients' health, linguistic barriers and religious or cultural differences, many healthcare providers experience difficulties in decoding language of distress and unfamiliar expressions, as well as cultural idioms of distress (Degni et al., 2012; Delilovic et al., 2018; Reynolds and White, 2010; Sundvall et al., 2018). In addition, physicians added that there is a lack of appropriate training programmes, which could help them to deal with asylum seekers and refugees in need of mental health services (Misra et al., 2006a). Healthcare providers reported that their evaluation of the health seeking of immigrants, asylum seekers and refugees residing in Europe depends on factors such as quality of communication and communication style between patients and healthcare providers, quality of interpreting services, whether the perspectives of patients and physicians are combined in healthcare services and a mutual understanding of cultural similarities and differences between healthcare professionals and users (Degni et al., 2012; Koehn, 2006; Sundvall et al., 2018). These findings, from an information point of view, can shed light on topics such as the importance of providing guidelines, tools and information related to providing special health-related services for the patients (Delilovic et al., 2018).

\section{Discussion and conclusion}

The results of this systematic review study show the health-seeking behaviours of immigrants, asylum seekers, and refugees in Europe have been analysed in a number of disciplines, ranging from medical science to health communication science. Findings from a systematic review of 57 articles revealed that this subject has been studied using qualitative, quantitative and mixed methods approaches. The articles included in the review looked at both the viewpoints of healthcare providers and patients, but the majority of them concentrated on only one.

We reinterpreted the information seeking and communication model (ISCM) to categorise, label and interpret the findings. Using the ISCM helped us to track health-seeking behaviour and health information sharing and communication between users (our target population) and healthcare providers. The advantage of the ISCM is that it allows to observe information sharing between patients and healthcare providers from the starting point to the evaluation of the acquired health information (Robson and Robinson, 2015). Applying this method also helped us to capture and interpret health-seeking behaviours of asylum seekers, refugees and immigrants while considering contextual and environmental influential factors.

The findings of the reviewed articles emphasise the significant role played by religion, beliefs and cultural norms in the healthcare-seeking behaviour of the studied groups (e.g. Hjelm and Apelqvist, 2016; Morawa and Erim, 2018; Onyigbuo et al., 2016; Onyigbuo et al., 2018; Papadopoulos et al., 2003; Straiton et al., 2018; Teunissen et al., 2014). The findings show that there are limited number of studies on information-seeking behaviours of the studied groups, and the majority of studies have focused on healthcare services provision, limitations, and facilitators. Therefore, this systematic review cannot provide clear answers to all questions related to health information needs, uses and the efficiency of the processes for both healthcare providers and users. However, the results showed the importance of providing health-related information on topics related to mental health, sexual health and HIV and pregnancy and childbirth for immigrants, asylum seekers and refugees living in Europe 
(e.g. Barkensjö et al., 2018; Dias et al., 2020; Kleinert et al., 2019; Straiton et al., 2018). Moreover, the results highlight the role of friendship and individual networks, and religious communities as first-hand health information sources for the studied populations (Devillanova, 2008; Ekblad et al., 2012; Thomas, 2010).

Common barriers in using and assessing health information or services are the difficulties to navigate or negotiate health related issues, to get an appointment for treatment, to assess the quality of the received treatment, to access the required healthcare services and to know one's medical services rights (Erdsiek et al., 2017; Kang et al., 2019; Mattila et al., 2016; Nikendei et al., 2019). The findings also show alternative health-seeking strategies such as using transnational health networks to cope with the aforementioned barriers (Thomas, 2010). Researchers also report that health literacy and educational level play a significant role in adapting to health-seeking approaches and strategies (Lecerof et al., 2011; Wångdahl et al., 2018).

The studies highlighted the importance of adopting a cross-cultural approach in providing health services and health information, specifically regarding the adaptation of measurement tools in terms of translation, cultural norms and values (Gerritsen et al., 2004). For example, mental health problems are a taboo topic in the African and Asian cultures. Lack of knowledge or lack of trust in physicians as well as general barriers to accessing healthcare services are also considered important factors influencing the health-seeking behaviour of immigrants living in Europe (Teunissen et al., 2014).

This research adds to the body of knowledge by revealing new details about the health (information) seeking behaviours of asylum seekers, refugees and immigrants in Europe, as well as new insights into this phenomenon from the perspective of healthcare providers. Findings of the reviewed studies were arranged into nine broad themes (see Table 2). Half of the studies included in the review covered particular health issues; however, mental health and parental health were the most common among the studied subjects. Furthermore, almost half of the articles did not focus on any particular health issue and mainly discussed the health-seeking behaviour of this particular population on a more general level. Among the studies focusing on a specific health issue, the majority investigated topics related to mental health, possibly due to the prevalence of stress experienced during the process of becoming an immigrant, an asylum seeker or a refugee. Therefore, it can be argued that the provision of information related to psychological health is highly needed by ethnic minorities living in Europe. More attention should be paid to healthcare providers and users' search, use and assessment of healthcare information and services. One major result of this review study was not only revealing the overall lack of studies focusing the health information behaviour of the studied population but also showing the lack of findings related to information in the studies we reviewed. In contrast to similar studies in the USA (e.g. Chen et al., 2010; Galeshi et al., 2018; Lee, 2018; Shin and Maupome, 2017; Yoon and Huang, 2017; Woodall et al., 2009), this topic is surprisingly neglected and our review points to an urgent need for additional studies in the European context.

\section{Implications}

Immigrants, asylum seekers and refugees experience numerous health service needs. This systematic review highlighted the importance of addressing these issues. The results of this study have some implications for healthcare providers, health policymakers and relevant authorities. First, the review results identified health services commonly sought by the studied population, including those related to mental health, perinatal health, pregnancy and childbirth, oral health, diabetes, diet health, cardiovascular health and sexual health and HIV. Our findings identified an area of concern related to mental health services and relevant health information for these groups. As such, it is suggested that healthcare providers pay more attention to these 
$\mathrm{JD}$

78,7

concerns. Second, this review identified the role of healthcare providers' attitudes and of users' trust in them in relation to health services selection. These behavioural factors must be taken into consideration when providing health services for these groups. The results also highlighted the need for culturally specific and accurate health information targeted towards immigrants, asylum seekers and refugees in Europe. Health services providers and health professionals should develop services and information materials that are culturally specific for these population groups. The health services and health information should be pilot tested in these groups to ensure that they meet the occurring health (information) needs. The results also shed light on the need for cultural competence among healthcare providers, so that they can better address the needs of these users. Finally, the findings underline the importance of developing a patient-provider communication approach aiming at the improvement of encounters and communication between healthcare providers and immigrants in Europe. Additional studies should be conducted to explore how culturally specific health information can be delivered to this population.

\section{Limitations}

The search strategy of this review initially focused on the health information-seeking behaviours of immigrants, asylum seekers and refugees in Europe. However, we decided to broaden the search from health information-seeking behaviours to health-seeking behaviours, in order to include more relevant studies. We are aware that there may be relevant references concerning other minorities in Europe. However, we focused on the healthcare needs of asylum seekers, refugees and immigrants, without including those of other local minorities. We also acknowledge that this systematic review may not represent all relevant fields, as the scientific databases used in this review did not necessarily contain references to all the key publications. However, we are confident that the articles examined and evaluated in this review provide an overall overview of the body of academic publications within this multidisciplinary area of research.

\section{Notes}

1. A software package for retrieving and analyzing academic citations from different scientific and open access databases.

2. See https://rayyan.qcri.org/

\section{References}

Barkensjö, M., Greenbrook, J.T.V., Rosenlundh, J., Ascher, H. and Elden, H. (2018), “The need for trust and safety inducing encounters: a qualitative exploration of women's experiences of seeking perinatal care when living as undocumented migrants in Sweden", BMC Pregnancy and Childbirth, Vol. 18 No. 1, pp. 1-17.

Bartolomei, J., Baeriswyl-Cottin, R., Framorando, D., Kasina, F., Premand, N., Eytan, A. and Khazaal, Y. (2016), "What are the barriers to access to mental healthcare and the primary needs of asylum seekers? A survey of mental health caregivers and primary care workers", $B M C$ Psychiatry, Vol. 16 No. 1, pp. 1-8.

Biswas, D., Kristiansen, M., Krasnik, A. and Norredam, M. (2011), "Access to healthcare and alternative health-seeking strategies among undocumented migrants in Denmark", BMC Public Health, Vol. 11 No. 1, pp. 1-11.

Blackwell, D., Holden, K. and Tregoning, D. (2002), "An interim report of health needs assessment of asylum seekers in Sunderland and North Tyneside", Public Health, Vol. 116 No. 4, pp. 221-226. 
Bozorgmehr, K., Biddle, L., Preussler, S., Mueller, A. and Szecsenyi, J. (2018), "Differences in pregnancy outcomes and obstetric care between asylum seeking and resident women: a cross-sectional study in a German federal state, 2010-2016”, BMC Pregnancy and Childbirth, Vol. 18 No. 1, pp. 417-1.

Carruthers, E. and Oakeshott, P. (2019), "Refugee and asylum seeker usage of primary care: medical student survey at two inner-city general practices", Education for Primary Care : An Official Publication of the Association of Course Organisers, National Association of GP Tutors, World Organisation of Family Doctors, Vol. 30 No. 4, pp. 248-250.

Chen, C., Kendall, J. and Shyu, Y.L. (2010), "Grabbing the rice straw: health information seeking in Chinese immigrants in the United States", Clinical Nursing Research, Vol. 19 No. 4, pp. 335-353.

Davison, B.J., Gleave, M.E., Goldenberg, S.L., Degner, L.F., Hoffart, D. and Berkowitz, J. (2002), "Assessing information and decision preferences of men with prostate cancer and their partners", Cancer Nursing, Vol. 25 No. 1, pp. 42-49.

Degni, F., Suominen, S., Essén, B., El Ansari, W. and Vehviläinen-Julkunen, K. (2012), “Communication and cultural issues in providing reproductive health care to immigrant women: health care providers' experiences in meeting the needs of Somali women living in Finland”, Journal of Immigrant and Minority Health, Vol. 14 No. 2, pp. 330-343.

Delilovic, S., Kulane, A., Åsbring, N., Marttila, A. and Lönnroth, K. (2018), "What value for whom? provider perspectives on health examinations for asylum seekers in Stockholm, Sweden", BMC Health Services Research, Vol. 18, 601, doi: 10.1007/s10903-011-9465-6.

Dervin, B. (2005), "Libraries reaching out with health information to vulnerable populations: guidance from research on information seeking and use", Journal of the Medical Library Association, Vol. 93 No. 4, pp. S74-S80.

Devillanova, C. (2008), "Social networks, information and health care utilization: evidence from undocumented immigrants in Milan", Journal of Health Economics, Vol. 27 No. 2, pp. 265-286.

Dias, S., Gama, A., Abrantes, P., Gomes, I., Fonseca, M., Reigado, V., Simões, D., Carreiras, E., Mora, C., Pinto Ferreira, A., Akpogheneta, O. and Martins, M.O. (2020), "Patterns of sexual risk behaviour, HIV infection, and use of health services among Sub-Saharan African migrants in Portugal”, Journal of Sex Research, Vol. 57 No. 7, pp. 906-913.

Djuretic, T., Crawford, M.J. and Weaver, T.D. (2007), "Role of qualitative research to inform design of epidemiological studies: a cohort study of mental health of migrants from the former Yugoslavia”, Journal of Mental Health, Vol. 16 No. 6, pp. 743-755.

Dorn, T., Ceelen, M., Tang, M., Browne, J.L., de Keijzer, K.J.C., Buster, M.C.A. and Das, K. (2011), "Health care seeking among detained undocumented migrants: a cross-sectional study", $B M C$ Public Health, Vol. 11 No. 1, pp. 1-9.

Ekblad, S., Linander, A. and Asplund, M. (2012), “An exploration of the connection between two meaning perspectives: an evidence-based approach to health information delivery to vulnerable groups of Arabic- and Somali-speaking asylum seekers in a Swedish context”, Global Health Promotion, Vol. 19 No. 3, pp. 21-31.

Ellis, D. (1989), “A behavioural model for information retrieval system design”, Journal of Information Science, Vol. 15 Nos 4-5, pp. 237-247.

Emtell Iwarsson, K., Larsson, E.C., Gemzell-Danielsson, K., Essén, B. and Klingberg-Allvin, M. (2019), "Contraceptive use among migrant, second-generation migrant and non-migrant women seeking abortion care: a descriptive cross-sectional study conducted in Sweden”, BMJ Sexual and Reproductive Health, Vol. 45 No. 0, pp. 118-126.

Erdsiek, F., Waury, D. and Brzoska, P. (2017), "Oral health behaviour in migrant and non-migrant adults in Germany: the utilization of regular dental check-ups", BMC Oral Health, Vol. 17 No. 1 , pp. 84-2. 
$\mathrm{JD}$

78,7

Eurostat (2020), Asylum Applications (non-EU) in the EU-28 Member States, 2008-2019, available at: https://ec.europa.eu/eurostat/statistics-explained/index.php/Asylum_statistics (accessed 22 March 2021).

Feldmann, C.T., Bensing, J.M., de Ruijter, A. and Boeije, H.R. (2007), "Afghan refugees and their general practitioners in The Netherlands: to trust or not to trust?", Sociology of Health and Illness, Vol. 29 No. 4, pp. 515-535.

Galeshi, R., Sharman, J. and Cai, J. (2018), "Influence of ethnicity, gender, and immigration status on millennials' behavior related to seeking health information", Equality, Diversity and Inclusion: An International Journal, Vol. 37 No. 6, pp. 621-631.

Garnweidner, L.M., Sverre Pettersen, K. and Mosdøl, A. (2013), "Experiences with nutrition-related information during antenatal care of pregnant women of different ethnic backgrounds residing in the area of Oslo, Norway", Midwifery, Vol. 29 No. 12, p. 130.

Garvin, B.J., Moser, D.K., Riegel, B., McKinley, S., Doering, L. and An, K. (2003), "Effects of gender and preference for information and control on anxiety early after myocardial infarction", Nursing Research, Vol. 52 No. 6, pp. 386-392.

Gerritsen, A.A., Bramsen, I., Devillé, W., van Willigen, L.H., Hovens, J.E. and van der Ploeg, H.M. (2004), "Health and health care utilisation among asylum seekers and refugees in The Netherlands: design of a study", BMC Public Health, Vol. 4 No. 1, pp. 1-10.

Gerritsen, A.A., Bramsen, I., Devillé, W., van Willigen, L.H., Hovens, J.E. and van der Ploeg, H.M. (2006), "Use of health care services by Afghan, Iranian, and Somali refugees and asylum seekers living in The Netherlands”, European Journal of Public Health, Vol. 16 No. 4, pp. 394-399.

Gewalt, S.C., Berger, S., Ziegler, S., Szecsenyi, J. and Bozorgmehr, K. (2018), "Psychosocial health of asylum-seeking women living in state-provided accommodation in Germany during pregnancy and early motherhood: a case study exploring the role of social determinants of health", $P l o S$ One, Vol. 13 No. 12, e0208007.

Gilgen, D., Maeusezahl, D., Salis Gross, C., Battegay, E., Flubacher, P., Tanner, M., Weiss, M.G. and Hatz, C. (2005), Impact of migration on illness experience and help-seeking strategies of patients from Turkey and Bosnia in primary health care in Basel, Health and Place, Vol. 11 No. 3, pp. 261-273.

Gondek, D. and Kirkbride, J.B. (2018), "Predictors of mental health help-seeking among Polish people living in the United Kingdom", BMC Health Services Research, Vol. 18 No. 1, pp. 1-12.

Goodman, L.F., Jensen, G.W., Galante, J.M., Farmer, D.L. and Taché, S. (2018), "A cross-sectional investigation of the health needs of asylum seekers in a refugee clinic in Germany", $B M C$ Family Practice, Vol. 19 No. 1, p. 64.

Hansen, A.R., Ekholm, O. and Kjøller, M. (2008), "Health behaviour among non-Western immigrants with Danish citizenship”, Scandinavian Journal of Public Health, Vol. 36 No. 2, pp. 205-210.

Hedemalm, A., Schaufelberger, M. and Ekman, I. (2008), "Symptom recognition and health care seeking among immigrants and native Swedish patients with heart failure", BMC Nursing, Vol. 7 No. 1, pp. 1-7.

Hjelm, K. and Apelqvist, J. (2016), "Influence of beliefs about health and illness on self-care and careseeking in foreign-born people with diabetic foot ulcers: dissimilarities related to origin", Journal of Wound Care, Vol. 25 No. 11, pp. 602-616.

Hoskins, C.N. and Haber, J. (2000), "Adjusting to breast cancer", AJN The American Journal of Nursing, Vol. 100 No. 4, pp. 26-33.

Huschke, S. (2014), "Fragile fabric: illegality knowledge, social capital and health-seeking of undocumented Latin American migrants in Berlin", Journal of Ethnic and Migration Studies, Vol. 40 No. 12, pp. 2010-2029.

Ingwersen, P. and Järvelin, K. (2005), "The sense of information: understanding the cognitive conditional information concept in relation to information acquisition”, in Crestani, F. and 
Ruthven, I. (Eds), Context: Nature, Impact, and Role. CoLIS 2005. Lecture Notes in Computer Science, Vol. 3507, Springer, Berlin, Heidelberg.

Jayaweera, H. and Quigley, M.A. (2010), "Health status, health behaviour and healthcare use among migrants in the UK: evidence from mothers in the Millennium Cohort study", Social Science and Medicine, Vol. 71 No. 5, pp. 1002-1010, 1982.

Jensen, N.K., Johansen, K.S., Kastrup, M., Krasnik, A. and Norredam, M. (2014), "Patient experienced continuity of care in the psychiatric healthcare system-a study including immigrants, refugees and ethnic Danes", International Journal of Environmental Research and Public Health, Vol. 11 No. 9, pp. 9739-9759.

Johnson, J.D. (1997), Cancer-related Information Seeking, Hampton Press, Cresskill.

Kang, C., Tomkow, L. and Farrington, R. (2019), "Access to primary health care for asylum seekers and refugees: a qualitative study of service user experiences in the UK", British Journal of General Practice : Journal of the Royal College of General Practitioners, Vol. 69 No. 685, pp. e537-e545.

Kleinert, E., Müller, F., Furaijat, G., Hillermann, N., Jablonka, A., Happle, C. and Simmenroth, A. (2019), "Does refugee status matter? Medical needs of newly arrived asylum seekers and resettlement refugees - a retrospective observational study of diagnoses in a primary care setting", Conflict and Health, Vol. 13 No. 1, pp. 1-9.

Knipscheer, J.W. and Kleber, R.J. (2001), "Help-seeking attitudes and utilization patterns for mental health problems of Surinamese migrants in The Netherlands", Journal of Counselling Psychology, Vol. 48 No. 1, pp. 28-38.

Knipscheer, J.W. and Kleber, R.J. (2005), "Help-seeking behaviour regarding mental health problems of Mediterranean migrants in The Netherlands: familiarity with care, consultation attitude and use of services", International Journal of Social Psychiatry, Vol. 51 No. 4, pp. 372-382.

Koehn, P.H. (2006), "Health-care outcomes in ethnoculturally discordant medical encounters: the role of physician transnational competence in consultations with asylum seekers", Journal of Immigrant and Minority Health, Vol. 8 No. 2, pp. 137-147.

Kralj, L. and Barriball, L. (2004), "Online information on primary care services for refugees and asylum-seekers", British Journal of Community Nursing, Vol. 9 No. 3, pp. 115-121.

Laban, C.J., Komproe, I.H., Gernaat, H.B. and de Jong, J.T. (2008), "The impact of a long asylum procedure on quality of life, disability and physical health in Iraqi asylum seekers in The Netherlands", Social Psychiatry and Psychiatric Epidemiology, Vol. 43 No. 7, pp. 507-515.

Lalazaryan, A. and Zare-Farashbandi, F. (2014), "A review of models and theories of health information seeking behavior", International Journal of Health System and Disaster Management, Vol. 2 No. 4, pp. 193-203.

Lambert, S.D. and Loiselle, C.G. (2007), "Health information seeking behaviour", Qualitative Health Research, Vol. 17 No. 8, pp. 1006-1019.

Leavey, G., Guvenir, T., Haase-Casanovas, S. and Dein, S. (2007), "Finding help: Turkish-speaking refugees and migrants with a history of psychosis", Transcultural Psychiatry, Vol. 44 No. 2, pp. 258-274.

Lecerof, S.S., Westerling, R., Moghaddassi, M. and Östergren, P.O. (2011), "Health information for migrants: the role of educational level in prevention of overweight", Scandinavian Journal of Public Health, Vol. 39 No. 2, pp. 172-178.

Lee, H.S. (2018), “A comparative study on the health information needs, seeking and source preferences among mothers of young healthy children: American mothers compared to recent immigrant Korean mothers", Information Research: An International Electronic Journal, Vol. 23 No. 4 , pp. 1-28.

Maier, T. and Straub, M. (2011), "My head is like a bag full of rubbish": concepts of illness and treatment expectations in traumatized migrants", Qualitative Health Research, Vol. 21 No. 2, pp. 233-248. 
$\mathrm{JD}$

78,7

Mattila, A., Ghaderi, P., Tervonen, L., Niskanen, L., Pesonen, P., Anttonen, V. and Laitala, M.L. (2016), "Self-reported oral health and use of dental services among asylum seekers and immigrants in Finland-a pilot study", European Journal of Public Health, Vol. 26 No. 6, pp. 1006-1010.

McMunn, A.M., Mwanje, R., Paine, K. and Pozniak, A.L. (1998), "Health service utilization in London's African migrant communities: implications for HIV prevention”, AIDS Care, Vol. 10 No. 4, pp. 453-462.

Misra, T., Connolly, A.M. and Majeed, A. (2006a), "Addressing mental health needs of asylum seekers and refugees in a London Borough: epidemiological and user perspectives", Primary Health Care Research and Development, Vol. 7 No. 3, pp. 241-248.

Misra, T., Connolly, A.M., Klynman, N. and Majeed, A. (2006b), "Addressing mental health needs of asylum seekers and refugees in a London Borough: developing a service model", Primary Health Care Research and Development, Vol. 7 No. 3, pp. 249-256.

Morawa, E. and Erim, Y. (2018), "Health-related lifestyle behaviour and religiosity among firstgeneration immigrants of polish origin in Germany", International Journal of Environmental Research and Public Health, Vol. 15 No. 11, p. 2545.

Nikendei, C., Kindermann, D., Brandenburg-Ceynowa, H., Derreza-Greeven, C., Zeyher, V., Junne, F., Friederich, H.C. and Bozorgmehr, K. (2019), "Asylum seekers' mental health and treatment utilization in a three-month follow-up study after transfer from a state registration-and reception-center in Germany", Health Policy (Amsterdam, Netherlands), Vol. 123 No. 9, pp. 864-872.

O’Donnell, C.A., Higgins, M., Chauhan, R. and Mullen, K. (2007), "They think we're OK and we know we're not. A qualitative study of asylum seekers' access, knowledge and views to health care in the UK", BMC Health Services Research, Vol. 7 No. 1, pp. 1-11.

Onyigbuo, C.C., Alexis-Garsee, C. and van den Akker, O. (2016), "Nigerian Clergy and healthcare professionals' perceptions of health-seeking behaviours among Nigerian immigrants in the UK", Mental Health, Religion and Culture, Vol. 19 No. 10, pp. 1043-1055.

Onyigbuo, C.C., Alexis-Garsee, C. and van den Akker, O. (2018), "Predicting attitudes towardss seeking medical care among Nigerian immigrants in the UK", Mental Health, Religion and Culture, Vol. 21 No. 8, pp. 810-824.

Palmer, D. (2007), "An exploration into the impact of the resettlement experience, traditional health beliefs and customs on mental ill-health and suicide rates in the Ethiopian community in London”, International Journal of Migration, Health and Social Care, Vol. 3 No. 1, pp. 44-55.

Papadopoulos, R., Lay, M., Lees, S. and Gebrehiwot, A. (2003), "The impact of migration on health beliefs and behaviours: the case of Ethiopian refugees in the UK", Contemporary Nurse, Vol. 15 No. 3, pp. 210-221.

Ransom, S., Jacobsen, P.B., Schmidt, J.E. and Andrykowski, M.A. (2005), "Relationship of problemfocused coping strategies to changes in quality-of-life following treatment for early-stage breast cancer", Journal of Pain and Symptom Management, Vol. 30 No. 3, pp. 243-253.

Rees, C.E. and Bath, P.A. (2000), "The psychometric properties of the Miller Behavioural Style Scale with adult daughters of women with early breast cancer: a literature review and empirical study", Journal of Advanced Nursing, Vol. 32 No. 2, pp. 366-374.

Reynolds, B. and White, J. (2010), "Seeking asylum and motherhood: health and wellbeing needs", Community Practitioner : The Journal of the Community Practitioners' and Health Visitors' Association, Vol. 83 No. 3, pp. 20-23.

Robson, A. and Robinson, L. (2015), "The information seeking and communication model", Journal of Documentation, Vol. 71 No. 5, pp. 1043-1069.

Sansus, L., Ramiro Troitiño, D. and Kerikmäe, T. (2020), "Migration to Europe: a threat or an opportunity?", in Ramiro Troitiño, D., Kerikmäe, T., de la Guardia, R. and Pérez Sánchez, G. (Eds), The EU in the 21st Century, Springer, Cham, doi: 10.1007/978-3-030-38399-2_5. 
Shamseer, L., Moher, D., Clarke, M., Ghersi, D., Liberati, A., Petticrew, M., Shekelle, P. and Stewart, L.A. (2015), "Preferred reporting items for systematic review and meta-analysis protocols (PRISMA-P) 2015: elaboration and explanation”, British Medical Journal, Vol. 350, pp. 1-25.

Shin, Y. and Maupome, G. (2017), "Segmentation of Mexican-heritage immigrants: acculturation typology and language preference in health information seeking", Journal of Immigrant and Minority Health, Vol. 19 No. 5, pp. 1163-1173.

Sørensen, K., Van den Broucke, S., Fullam, J., Doyle, G., Pelikan, J., Slonska, Z. and Brand, H. (2012), "Health literacy and public health: a systematic review and integration of definitions and models", BMC Public Health, Vol. 12 No. 1, pp. 1-13.

Straiton, M.L., Ledesma, H.M.L. and Donnelly, T.T. (2018), “'It has not occurred to me to see a doctor for that kind of feeling": a qualitative study of Filipina immigrants' perceptions of help seeking for mental health problems", BMC Women's Health, Vol. 18 No. 1, pp. 1-11.

Sundvall, M., Titelman, D. and Bäärnhielm, S. (2018), "Challenges of combining perspectives: a qualitative study of the communication between female suicidal asylum seekers and mental health clinicians", Crisis: The Journal of Crisis Intervention and Suicide Prevention, Vol. 39 No. 5, pp. 326-334.

Teunissen, E., Sherally, J., van den Muijsenbergh, M., Dowrick, C., van Weel-Baumgarten, E. and van Weel, C. (2014), "Mental health problems of undocumented migrants (UMs) in The Netherlands: a qualitative exploration of help-seeking behaviour and experiences with primary care", British Medical Journal Open, Vol. 4 No. 11, e005738.

Thackeray, R. and Neiger, B.L. (2009), "A multidirectional communication model: implications for social marketing practice", Health Promotion Practice, Vol. 10 No. 2, pp. 171-175.

Thomas, F. (2010), "Transnational health and treatment networks: meaning, value and place in health seeking amongst southern African migrants in London", Health and Place, Vol. 16 No. 3, pp. 606-612.

Toar, M., O'Brien, K.K. and Fahey, T. (2009), "Comparison of self-reported health and healthcare utilisation between asylum seekers and refugees: an observational study", BMC Public Health, Vol. 9 No. 1, pp. 1-10.

Van Mol, C. and De Valk, H. (2016), Migration and Immigrants in Europe: A Historical and Demographic Perspective, Integration Processes and Policies in Europe Springer, Cham, pp. 31-55.

Wångdahl, J., Lytsy, P., Mårtensson, L. and Westerling, R. (2018), "Poor health and refraining from seeking healthcare are associated with comprehensive health literacy among refugees: a Swedish cross-sectional study", International Journal of Public Health, Vol. 63 No. 3, pp. 409-419.

Wilson, T.D. (1981), "On user studies and information needs", Journal of Documentation, Vol. 37 No. 1 , pp. 3-15.

Woodall, E.D., Taylor, V.M., Teh, C., Li, L., Acorda, E., Tu, S., Yasui, Y. and Hislop, T.G. (2009), "Sources of health information among Chinese immigrants to the Pacific Northwest", Journal of Cancer Education, Vol. 24 No. 4, pp. 334-340.

Yoon, J. and Huang, H. (2017), "Trends in health information-seeking behaviour in the US foreign-born population based on the health information national trends survey, 2005-2014", Information Research: An International Electronic Journal, Vol. 22 No. 3, pp. 1-26.

\section{Health information and healthcare services}




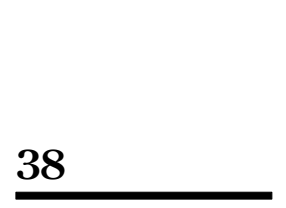

\begin{tabular}{|c|c|c|c|c|c|}
\hline ID & Source & Country & $\begin{array}{l}\text { Sample } \\
\text { size }\end{array}$ & Sample study group & Category \\
\hline 1 & $\begin{array}{l}\text { Nikendei et al. } \\
\text { (2019) }\end{array}$ & Germany & 228 & $\begin{array}{l}\text { Asian, African, } \\
\text { European, Middle } \\
\text { East }\end{array}$ & User assess/use/ignore \\
\hline 2 & $\begin{array}{l}\text { Kleinert et al. } \\
\text { (2019) }\end{array}$ & Germany & 2252 & African, Middle East & $\begin{array}{l}\text { User need/wants/goals/ } \\
\text { perception }\end{array}$ \\
\hline 3 & Kang et al. (2019) & UK & 18 & African, Middle East & User assess/use/ignore \\
\hline 4 & $\begin{array}{l}\text { Carruthers and } \\
\text { Oakeshott (2019) }\end{array}$ & UK & 35 & African & User assess/use/ignore \\
\hline 5 & $\begin{array}{l}\text { Morawa and } \\
\text { Erim (2018) }\end{array}$ & Germany & 257 & European & $\begin{array}{l}\text { Seek Information: activity/ } \\
\text { feeling/thought }\end{array}$ \\
\hline 6 & $\begin{array}{l}\text { Delilovic et al. } \\
\text { (2018) }\end{array}$ & Sweden & 41 & N/A & $\begin{array}{l}\text { Provider needs/wants/goals/ } \\
\text { perspectives | Provider } \\
\text { communication medium/ } \\
\text { process }\end{array}$ \\
\hline 7 & $\begin{array}{l}\text { Barkensjö et al. } \\
(2018)\end{array}$ & Sweden & 13 & $\begin{array}{l}\text { African, European, } \\
\text { Middle East }\end{array}$ & $\begin{array}{l}\text { Choosing source: credibility/ } \\
\text { utility }\end{array}$ \\
\hline 8 & $\begin{array}{l}\text { Straiton et al. } \\
\text { (2018) }\end{array}$ & Norway & 14 & Asian & $\begin{array}{l}\text { Seek Information: activity/ } \\
\text { feeling/thought }\end{array}$ \\
\hline 9 & $\begin{array}{l}\text { Wångdahl et al. } \\
\text { (2018) }\end{array}$ & Sweden & 513 & African, Middle East & $\begin{array}{l}\text { Outcome actions/decisions/ } \\
\text { knowledge }\end{array}$ \\
\hline 10 & $\begin{array}{l}\text { Onyigbuo et al. } \\
\text { (2018) }\end{array}$ & UK & 297 & African & $\begin{array}{l}\text { Seek Information: activity/ } \\
\text { feeling/thought }\end{array}$ \\
\hline 11 & Degni et al. (2012) & Finland & 25 & N/A & $\begin{array}{l}\text { Provider communication } \\
\text { medium/process }\end{array}$ \\
\hline 12 & $\begin{array}{l}\text { Erdsiek et al. } \\
(2017)\end{array}$ & Germany & 22.050 & N/A & User assess/use/ignore \\
\hline 13 & $\begin{array}{l}\text { Mattila et al. } \\
\text { (2016) }\end{array}$ & Finland & 38 & $\begin{array}{l}\text { African, European, } \\
\text { Middle East }\end{array}$ & User assess/use/ignore \\
\hline 14 & $\begin{array}{l}\text { Hjelm and } \\
\text { Apelqvist (2016) }\end{array}$ & Sweden & 26 & $\begin{array}{l}\text { Southern American, } \\
\text { European, Middle } \\
\text { East }\end{array}$ & $\begin{array}{l}\text { Seek Information: activity/ } \\
\text { feeling/thought }\end{array}$ \\
\hline 15 & $\begin{array}{l}\text { Lecerof } \text { et al. } \\
\text { (2011) }\end{array}$ & Sweden & 587 & Middle East & $\begin{array}{l}\text { Outcome actions/decisions/ } \\
\text { knowledge }\end{array}$ \\
\hline 16 & Thomas (2010) & UK & 39 & African & $\begin{array}{l}\text { User assess/use/ignore / User } \\
\text { communication medium// } \\
\text { process }\end{array}$ \\
\hline 17 & $\begin{array}{l}\text { Hansen et al. } \\
\text { (2008) }\end{array}$ & Denmark & 10.037 & $\begin{array}{l}\text { Asian, African, } \\
\text { European, Middle } \\
\text { East, Indian } \\
\text { Subcontinent }\end{array}$ & $\begin{array}{l}\text { User assess/use/ignore | Seek } \\
\text { Information: activity/feeling/ } \\
\text { thought }\end{array}$ \\
\hline 18 & $\begin{array}{l}\text { Hedemalm et al. } \\
\text { (2008) }\end{array}$ & Sweden & 42 & $\begin{array}{l}\text { European and non- } \\
\text { European }\end{array}$ & $\begin{array}{l}\text { Seek Information: activity/ } \\
\text { feeling/thought }\end{array}$ \\
\hline 19 & $\begin{array}{l}\text { O'Donnell et al. } \\
\text { (2007) }\end{array}$ & UK & 52 & $\begin{array}{l}\text { Asian, African, } \\
\text { European, Middle } \\
\text { East, Indian } \\
\text { Subcontinent }\end{array}$ & $\begin{array}{l}\text { Outcome actions/decisions/ } \\
\text { knowledge }\end{array}$ \\
\hline 20 & $\begin{array}{l}\text { Gerritsen et al. } \\
\text { (2006) }\end{array}$ & $\begin{array}{l}\text { The } \\
\text { Netherlands }\end{array}$ & 410 & African, Middle East & User assess/use/ignore \\
\hline \multirow[t]{2}{*}{21} & $\begin{array}{l}\text { Knipscheer and } \\
\text { Kleber (2005) }\end{array}$ & $\begin{array}{l}\text { The } \\
\text { Netherlands }\end{array}$ & 292 & African, Middle East & User assess/use/ignore \\
\hline & & & & & (continued) \\
\hline
\end{tabular}

(continued)

\section{Table A1.}

Records and categories in the systematic reviews 


\begin{tabular}{|c|c|c|c|c|c|c|}
\hline ID & Source & Country & $\begin{array}{l}\text { Sample } \\
\text { size }\end{array}$ & Sample study group & Category & information \\
\hline 22 & Gilgen et al. (2005) & Switzerland & 235 & $\begin{array}{l}\text { European, Middle } \\
\text { East }\end{array}$ & $\begin{array}{l}\text { Seek Information: activity/ } \\
\text { feeling/thought }\end{array}$ & services \\
\hline 23 & $\begin{array}{l}\text { Kralj and } \\
\text { Barriball (2004) }\end{array}$ & UK & N/A & $\mathrm{N} / \mathrm{A}$ & $\begin{array}{l}\text { Choosing source: credibility/ } \\
\text { utility }\end{array}$ & \\
\hline 24 & $\begin{array}{l}\text { Teunissen } \text { et al. } \\
\text { (2014) }\end{array}$ & $\begin{array}{l}\text { The } \\
\text { Netherlands }\end{array}$ & 15 & $\begin{array}{l}\text { Asian, African, } \\
\text { Indian Subcontinent }\end{array}$ & $\begin{array}{l}\text { Seek Information: activity/ } \\
\text { feeling/thought }\end{array}$ & 39 \\
\hline 25 & $\begin{array}{l}\text { Papadopoulos } \\
\text { et al. (2003) }\end{array}$ & UK & 106 & African & $\begin{array}{l}\text { Choosing source: credibility/ } \\
\text { utility | User need/wants/goals/ } \\
\text { perception }\end{array}$ & \\
\hline 26 & $\begin{array}{l}\text { Knipscheer and } \\
\text { Kleber (2001) }\end{array}$ & $\begin{array}{l}\text { The } \\
\text { Netherlands }\end{array}$ & 185 & Southern American & $\begin{array}{l}\text { User assess/use/ignore | Seek } \\
\text { Information: activity/feeling/ } \\
\text { thought }\end{array}$ & \\
\hline 27 & $\begin{array}{l}\text { Ekblad et al. } \\
\text { (2012) }\end{array}$ & Sweden & 626 & African, Middle East & $\begin{array}{l}\text { User communication medium/ } \\
\text { process }\end{array}$ & \\
\hline 28 & $\begin{array}{l}\text { McMunn } \\
\text { et al.,1998 }\end{array}$ & UK & 118 & African & User assess/use/ignore & \\
\hline 29 & $\begin{array}{l}\text { Onyigbuo et al. } \\
\text { (2016) }\end{array}$ & UK & 6 & African & $\begin{array}{l}\text { Seek Information: activity/ } \\
\text { feeling/thought }\end{array}$ & \\
\hline 30 & $\begin{array}{l}\text { Gerritsen et al. } \\
\text { (2004) }\end{array}$ & $\begin{array}{l}\text { The } \\
\text { Netherlands }\end{array}$ & 600 & African, Middle East & User assess/use/ignore & \\
\hline 31 & $\begin{array}{l}\text { Goodman et al. } \\
\text { (2018) }\end{array}$ & Germany & 2.232 & $\begin{array}{l}\text { African, European, } \\
\text { Middle East }\end{array}$ & $\begin{array}{l}\text { User (need/wants/goals/ } \\
\text { perception) }\end{array}$ & \\
\hline 32 & Dorn et al. (2011) & $\begin{array}{l}\text { The } \\
\text { Netherlands }\end{array}$ & 224 & $\begin{array}{l}\text { Asian, African, } \\
\text { European, Middle } \\
\text { East, Southern } \\
\text { American }\end{array}$ & $\begin{array}{l}\text { Seek Information (activity/ } \\
\text { feeling/thought) }\end{array}$ & \\
\hline 33 & Toar et al. (2009) & Ireland & 60 & $\begin{array}{l}\text { Asian, African, } \\
\text { European, Middle } \\
\text { East }\end{array}$ & User (assess/use/ignore) & \\
\hline 34 & $\begin{array}{l}\text { Misra et al. } \\
\text { (2006b) }\end{array}$ & UK & 14 & $\mathrm{~N} / \mathrm{A}$ & $\begin{array}{l}\text { Provider (needs/wants/goals/ } \\
\text { perspectives) }\end{array}$ & \\
\hline 35 & $\begin{array}{l}\text { Biswas et al. } \\
\text { (2011) }\end{array}$ & Denmark & 10 & Indian subcontinent & Future Information Seeking & \\
\hline 36 & $\begin{array}{l}\text { Jayaweera and } \\
\text { Quigley (2010) }\end{array}$ & UK & N/A & $\begin{array}{l}\text { African, European, } \\
\text { Meddle-American, } \\
\text { Indian Subcontinent }\end{array}$ & User (assess/use/ignore) & \\
\hline 37 & $\begin{array}{l}\text { Devillanova } \\
(2008)\end{array}$ & Italy & 10.254 & $\begin{array}{l}\text { Asian, African, } \\
\text { European, Middle } \\
\text { and Southern } \\
\text { American }\end{array}$ & $\begin{array}{l}\text { User (communication medium/ } \\
\text { process) }\end{array}$ & \\
\hline 38 & $\begin{array}{l}\text { Sundvall et al. } \\
\text { (2018) }\end{array}$ & Sweden & 18 & $\begin{array}{l}\text { African, Middle } \\
\text { East, Indian } \\
\text { subcontinent }\end{array}$ & $\begin{array}{l}\text { Provider (needs/wants/goals/ } \\
\text { perspectives) | Provider } \\
\text { (assess, use or dismiss } \\
\text { information) | Provider } \\
\text { (communication medium or } \\
\text { process) }\end{array}$ & \\
\hline 39 & Koehn (2006) & Finland & 35 & $\begin{array}{l}\text { Asian, African, } \\
\text { European, Middle } \\
\text { East }\end{array}$ & $\begin{array}{l}\text { Provider (communication } \\
\text { medium or process) | Outcome } \\
\text { (actions/decisions/knowledge) }\end{array}$ & \\
\hline 40 & Huschke (2014) & Germany & 35 & $\begin{array}{l}\text { Southern American, } \\
\text { Middle American }\end{array}$ & $\begin{array}{l}\text { Choosing source (credibility/ } \\
\text { utility) }\end{array}$ & \\
\hline 41 & $\begin{array}{l}\text { Gondek and } \\
\text { Kirkbride (2018) }\end{array}$ & UK & 536 & European & $\begin{array}{l}\text { User (need/wants/goals/ } \\
\text { perception) }\end{array}$ & \\
\hline
\end{tabular}




\begin{tabular}{|c|c|c|c|c|c|}
\hline ID & Source & Country & $\begin{array}{l}\text { Sample } \\
\text { size }\end{array}$ & Sample study group & Category \\
\hline 42 & $\begin{array}{l}\text { Misra et al. } \\
(2006 \mathrm{a})\end{array}$ & UK & 10 & $\begin{array}{l}\text { African, European, } \\
\text { Middle East }\end{array}$ & $\begin{array}{l}\text { User (need/wants/goals/ } \\
\text { perception) }\end{array}$ \\
\hline 43 & $\begin{array}{l}\text { Blackwell et al. } \\
\text { (2002) }\end{array}$ & UK & 397 & $\begin{array}{l}\text { Asian, African, } \\
\text { European, Middle } \\
\text { East }\end{array}$ & $\begin{array}{l}\text { User (need/wants/goals/ } \\
\text { perception) }\end{array}$ \\
\hline 44 & $\begin{array}{l}\text { Djuretic et al. } \\
\text { (2007) }\end{array}$ & UK & 19 & European & $\begin{array}{l}\text { User (need/wants/goals/ } \\
\text { perception) | User (assess/use/ } \\
\text { ignore) }\end{array}$ \\
\hline 45 & $\begin{array}{l}\text { Feldmann et al. } \\
(2007)\end{array}$ & $\begin{array}{l}\text { The } \\
\text { Netherlands }\end{array}$ & 24 & Middle East & $\begin{array}{l}\text { User communication medium/ } \\
\text { process }\end{array}$ \\
\hline 46 & Jensen et al. (2014) & Denmark & 15 & $\begin{array}{l}\text { African, European, } \\
\text { Middle East, Indian } \\
\text { subcontinent }\end{array}$ & $\begin{array}{l}\text { Seek Information (activity/ } \\
\text { feeling/thought) }\end{array}$ \\
\hline 47 & $\begin{array}{l}\text { Leavey et al. } \\
(2007)\end{array}$ & UK & 9 & Middle East & $\begin{array}{l}\text { Seek Information (activity/ } \\
\text { feeling/thought) }\end{array}$ \\
\hline 48 & $\begin{array}{l}\text { Maier and Straub } \\
\text { (2011) }\end{array}$ & Switzerland & 13 & $\begin{array}{l}\text { African, European, } \\
\text { Middle East }\end{array}$ & $\begin{array}{l}\text { User (need/wants/goals/ } \\
\text { perception) }\end{array}$ \\
\hline 49 & Palmer (2007) & UK & 10 & African & $\begin{array}{l}\text { User (need/wants/goals/ } \\
\text { perception) | Seek Information } \\
\text { (activity/feeling/thought) } \mid \\
\text { Provider (needs/wants/goals/ } \\
\text { perspectives) }\end{array}$ \\
\hline 50 & $\begin{array}{l}\text { Bozorgmehr et al. } \\
\text { (2018) }\end{array}$ & Germany & 19.864 & N/A & $\begin{array}{l}\text { Outcome actions/decisions/ } \\
\text { knowledge }\end{array}$ \\
\hline 51 & $\begin{array}{l}\text { Reynolds and } \\
\text { White (2010) }\end{array}$ & UK & 11 & N/A & $\begin{array}{l}\text { Selecting source (credibility } \\
\text { and utility) } \mid \text { Provider } \\
\text { (communication medium or } \\
\text { process) }\end{array}$ \\
\hline 52 & $\begin{array}{l}\text { Gewalt et al. } \\
\text { (2018) }\end{array}$ & Germany & 21 & $\begin{array}{l}\text { Asian, African, } \\
\text { European, Middle } \\
\text { East }\end{array}$ & $\begin{array}{l}\text { User (need/wants/goals/ } \\
\text { perception) }\end{array}$ \\
\hline 53 & Laban et al. (2008) & $\begin{array}{l}\text { The } \\
\text { Netherlands }\end{array}$ & 294 & Middle East & $\begin{array}{l}\text { User (need/wants/goals/ } \\
\text { perception) }\end{array}$ \\
\hline 54 & $\begin{array}{l}\text { Bartolomei et al. } \\
\text { (2016) }\end{array}$ & Switzerland & 135 & N/A & $\begin{array}{l}\text { User (need/wants/goals/ } \\
\text { perception) }\end{array}$ \\
\hline 55 & $\begin{array}{l}\text { Emtell Iwarsson } \\
\text { et al. (2019) }\end{array}$ & Sweden & 637 & $\begin{array}{l}\text { Asian, African, } \\
\text { European, Middle } \\
\text { East, Southern } \\
\text { American }\end{array}$ & $\begin{array}{l}\text { User (need/wants/goals/ } \\
\text { perception) }\end{array}$ \\
\hline 56 & Dias et al. (2020) & Portugal & 790 & African & User (assess/use/ignore) \\
\hline 57 & $\begin{array}{l}\text { Garnweidner } \\
\text { et al. (2013) }\end{array}$ & Norway & 15 & N/A & $\begin{array}{l}\text { User (need/wants/goals/ } \\
\text { perception) | User } \\
\text { (communication medium/ } \\
\text { process) | Seek Information } \\
\text { (activity/feeling/thought) }\end{array}$ \\
\hline
\end{tabular}

Table A1. 
Appendix 2

\begin{tabular}{|c|c|c|c|c|}
\hline Means of data gathering & $N=57$ & $\%$ & ID & services \\
\hline Administrative data of hospital & 1 & 1.75 & 50 & \\
\hline Chart review & 1 & 1.75 & 2 & \\
\hline Consulting with professionals & 1 & 1.75 & 51 & 41 \\
\hline Focus group discussions & 2 & 3.51 & 16,27 & \\
\hline Focus group discussions and interviews & 4 & 7.02 & $11,19,40,44$ & \\
\hline Interview and Questionnaire & 1 & 1.75 & 1 & \\
\hline Interviews & 11 & 19.30 & $13,20,34,39,45,46,47,49,56,6,7$ & \\
\hline Open data source & 5 & 8.77 & $17,31,36,37,38$ & \\
\hline Questionnaire & 9 & 15.79 & $10,15,30,33,43,5,55,57,9$ & \\
\hline Questionnaire and open-ended interviews & 1 & 1.75 & 26 & \\
\hline $\begin{array}{l}\text { Semi-structured interview and Semi-structured } \\
\text { questionnaire }\end{array}$ & 1 & 1.75 & 25 & \\
\hline Semi-structured interviews & 10 & 17.54 & $14,18,21,22,29,3,42,48,52,8$ & \\
\hline Semi-structured interviews and observations & 1 & 1.75 & 35 & \\
\hline Semi-structured interviews and thematic analysis & 1 & 1.75 & 24 & \\
\hline Semi-structured questionnaire & 1 & 1.75 & 28 & \\
\hline Structured interview & 1 & 1.75 & 53 & \\
\hline Structured interviews and open data source & 1 & 1.75 & 32 & \\
\hline Survey & 3 & 5.26 & $23,4,41$ & \\
\hline Telephone survey & 1 & 1.75 & 12 & \\
\hline \multicolumn{5}{|l|}{ Place of recruitment } \\
\hline Hospital/medical clinic and health centre & 19 & 33.33 & $\begin{array}{l}1,11,14,18,2,21,22,29,31,4,40,46 \\
48,50,51,55,56,58,6\end{array}$ & \\
\hline Informal social network & 2 & 3.51 & 24,41 & \\
\hline $\begin{array}{l}\text { Integration program, language school, university } \\
\text { or educational centres }\end{array}$ & 2 & 3.51 & 9,13 & \\
\hline Migration authorities and related organizations & 3 & 5.26 & $6,27,34$ & \\
\hline NGO, charity and other associations & 4 & 7.02 & $35,40,57,7$ & \\
\hline Online, social-media, telephone, or postal survey & 4 & 7.02 & $12,15,23,41$ & Table A2. \\
\hline Refugee camp or refugee reception & 10 & 17.54 & $13,20,30,32,33,39,44,45,52,53$ & Description of included \\
\hline $\begin{array}{l}\text { Voluntary community, cultural community or } \\
\text { multicultural community }\end{array}$ & 16 & 28.07 & $\begin{array}{l}10,16,19,21,24,25,26,28,29,3,35,37 \\
42,49,5,8\end{array}$ & $\begin{array}{l}\text { studies (general } \\
\text { characteristic of }\end{array}$ \\
\hline Other & 6 & 10.53 & $17,36,38,43,47,54$ & the study) \\
\hline
\end{tabular}

\section{Corresponding author}

Hamed Ahmadinia can be contacted at: hamed.ahmadinia@abo.fi

For instructions on how to order reprints of this article, please visit our website:

www.emeraldgrouppublishing.com/licensing/reprints.htm

Or contact us for further details: permissions@emeraldinsight.com 